\title{
Clinical Profile and Outcome of Children Infected with SARS-CoV-2
}

\author{
Vinod H. Ratageri ${ }^{1}$ (D) Shivaleela $\mathrm{M}^{1} \cdot$ Gayatri R. Pawar $^{1} \cdot$ Shivanand Illalu ${ }^{1} \cdot$ Prakash K. Wari $^{1}$
}

Received: 7 December 2020 / Accepted: 25 February 2021 / Published online: 9 April 2021

(C) Dr. K C Chaudhuri Foundation 2021

To the Editor: Children of all ages are susceptible to coronavirus disease (COVID)-19 and accounted for 1\%-5\% of diagnosed cases across the world [1]. Exact Indian data on children are not yet known; however data from Tamil Nadu showed $5.6 \%$ [2]. We describe, clinical profile and outcome of children (1 mo to $12 \mathrm{y}$ ), who were infected with SARS-CoV-2 [reverse transcription polymerase chain reaction (RT-PCR) confirmed], admitted at KIMS, Hubballi during April to September 2020. A total of 68 children were confirmed with SARS-CoV-2. Thirty nine (57\%) were female with F:M ratio 1.3:1 and with median age of $5.5 \mathrm{y}$ (IQR: $2,9.5 \mathrm{y}$ ). The majority age group affected was 6-12 y (47\%). Only 20 (29\%) were symptomatic at the time of admission, remaining were found to be positive for COVID-19 during family/contact/traveller's screening. Our observations noted that $71 \%$ (48) were mild/asymptomatic, $26 \%$ (18) moderate, 3\% (02) severe, and none of these cases were critical as per severity classification of WHO. Among 20 (29\%) symptomatic cases, the common symptoms in descending frequency were fever $14(70 \%)$, cough 10 (51\%), difficulty in breathing 04 (20\%). Four children had gastrointestinal (GI) symptoms like loose stool and vomiting. Two children had co-morbidities (congenital heart disease and cerebral palsy). Six (9\%) children had leucopenia [white blood cells (WBC) < 5000]. Eight (12\%) had thrombocytopenia $(<1.5$ lakh). None of our children received any antiviral agents. Six children received antibiotics (amoxicillin). Repeat swab was taken for 18 cases after an average of $7 \mathrm{~d}$ and found negative. Average duration of hospital stay was $11 \mathrm{~d}$. There was no mortality in our study.

Vinod H. Ratageri

ratageri@rediffmail.com

1 Department of Pediatrics, Karnataka Institute of Medical Sciences, Hubballi 580021, Karnataka, India
Most of our COVID-19 children were asymptomatic. Among symptomatic children fever was predominant and GI symptoms were observed in few children. Systematic review by Ludvigsson also had similar observation [3]. The possible cause for GI manifestation would be the expression of angiotensin-converting enzyme 2 (ACE-2) receptors on all well-differentiated epithelial cells including enterocytes in small intestine [4]. All our symptomatic children improved with only supportive therapy.

\section{Declarations}

Conflict of Interest None.

\section{References}

1. Tezer H, Bedir DT. Novel coronavirus disease (COVID-19) in children. Turk J Med Sci. 2020;50(SI-1):592-603.

2. Gupta N, Praharaj I, Bhatnagar T, et al. Severe acute respiratory illness surveillance for coronavirus disease 2019, India, 2020. Indian J Med Res. 2020;151(2 \& 3):236-40.

3. Ludvigsson JF. Systematic review of COVID-19 in children shows milder cases and a better prognosis than adults. Acta Paediatr. 2020;109:1088-95.

4. Song R, Preston G, Yosypiv IV. Ontogeny of angiotensin converting enzyme 2. Pediatr Res. 2012;71:13-9.

Publisher's Note Springer Nature remains neutral with regard to jurisdictional claims in published maps and institutional affiliations. 